\title{
CONSULTORIA: O PAPEL DO CONSULTOR NAS ORGANIZAÇÕES PRIVADAS
}

Ananda Viana Bezerra, Irene Caíres da Silva, Luiz Gustavo Gonçalves de Lima, Sandra Cristina Pelegrini Giacomelli, Thais Rubia Ferreira Lepre

Universidade do Oeste Paulista - UNOESTE. Curso de Ciências Contábeis, Presidente Prudente - SP. E-mail: ananda_v@live.com

\section{RESUMO}

As organizações estão sujeitas a constantes mudanças, que são causadas por diversos fatores, e em alguns momentos os gestores necessitam de uma análise mais profunda sobre a atual realidade, e soluções para problemas existentes, nesse momento fica visível a importância do consultor empresarial. Aparentemente todos sabem que o trabalho de consultoria é muito importante, então quais seriam as dificuldades que os consultores se deparam ao executarem o seu trabalho? Diante dessa questão, foi adotado no presente artigo o método de pesquisa bibliográfica e abordagem qualitativa, visando além de responder o questionamento acima, contribuir para que os profissionais desta área tenham maior preparação para lidar com as possíveis dificuldades encontradas. Conclui se que para a prestação de uma consultoria de qualidade, o profissional deve estar técnica e intelectualmente preparado para lidar com as mais diversas situações, e estar ciente que o dialogo é palavra chave nesta profissão.

Palavras-chave: Consultoria, Consultor Externo, Cliente, Responsabilidade.

\section{CONSULTING: THE ROLE OF THE CONSULTANT IN PRIVATE ORGANIZATIONS}

\begin{abstract}
Organizations are subject to constant changes, which are caused by several factors, and in some instances managers need a deeper analysis of the current reality, and solutions to existing problems, this moment is visible the importance of business consultant. Apparently everyone knows that the consulting work is very important, so what are the problems that consultants face when carrying out their work? Faced with this issue, in this article was adopted the method of literature review and qualitative approach, aiming beyond answering the question above, contribute to the professionals in this field have greater preparedness to deal with possible difficulties. Concludes that for the provision of quality advice, the physician must be technically and intellectually prepared to deal with many different situations, and be aware that dialogue is the key word in this profession
\end{abstract}

Keywords: Consulting, External, Consultant, Client, Responsibility. 
INTRODUÇÃO E OBJETIVO

Os serviços contábeis são realizados técnica e formalmente de acordo com a legislação vigente. Porém, as mudanças são constantes, tornando-se necessário buscar a ajuda de profissionais especializados, não só para atualização das exigências legais, mas também para propor soluções e recomendar ações para que a organização atinja bons resultados e se consolide no mercado. Uma das ferramentas em destaque é a Consultoria Empresarial, que visa auxiliar o gestor na percepção de problemas e nas tomadas de decisões, com o intuito de desenvolver atitudes capazes de interagir com diversos setores da organização. O empresário pode optar pela consultoria interna, que conta com um profissional que faz parte do quadro de colaboradores e que acumulou conhecimentos e técnicas específicas, ou pela consultoria externa, executada por profissionais que estão fora do ambiente da empresa. Estes são contratados por um período de tempo determinado e trarão metodologias e técnicas eficazes na solução de problemas, tomada de decisões e orientação aos gestores de forma a mantê-los sempre atualizados para enfrentar as mudanças do mercado atual. É importante saber que o Consultor não tem controle direto quanto à execução das ações por ele propostas, cabendo esta responsabilidade ao Gerente. Portanto este estudo demonstra que uma eficiente consultoria desde o momento de constituição da empresa e ao longo de sua trajetória, implica na permanência da mesma no mercado. Então, quais são as dificuldades que os consultores externos se deparam nas organizações privadas? 0 presente trabalho se justifica pela necessidade de orientar os profissionais que pretendem ingressar na carreira de Consultor Externo, identificando os principais obstáculos que serão encontrados para a execução de seus trabalhos e também para os profissionais que já atuam nessa área, mas que ainda precisam se consolidar no mercado.

Neste sentido, o artigo tem o objetivo de identificar as dificuldades que os consultores externos se deparam para realização do seu trabalho nas organizações privadas.

\section{METODOLOGIA}

O presente artigo apresenta uma abordagem qualitativa, pautando o método de pesquisa exploratória do tipo bibliográfica como caminho a ser percorrido para atingir o objetivo proposto. Foi viabilizada através de doutrinas, artigos científicos, periódicos, sites oficiais, dentre outros.

\section{RESULTADOS}

Após a realização do presente estudo, tornou-se possível afirmar que, embora o papel do consultor externo nas organizações privadas seja imprescindível, pois o mesmo utiliza-se de 
metodologias e técnicas diferenciadas e eficazes para lidar com situações que fogem ao controle dos gestores, no direcionamento da empresa de modo que o problema que a tirou do seu foco seja solucionado, é preciso que o mesmo tenha competência técnica e intelectual para saber lidar com os desafios de relacionamento com pessoas em todos os níveis hierárquicos da empresa, conseguindo desta forma se solidificar no mercado de trabalho.

\section{DISCUSSÃO}

Após crescente desenvolvimento do parque industrial e comercial, em meio a um cenário globalizado, surge a necessidade de atualização e utilização de novas técnicas e metodologias para que a empresa continue atuando com sucesso no mercado. Diante desse cenário, o profissional contábil vislumbrou uma grande oportunidade para atuar na área de consultoria empresarial, assegurando desenvolvimento de conhecimentos técnicos e ótima possibilidade de crescimento profissional.

Oliveira (2003, p. 21) nos orienta que:

Consultoria empresarial é um processo interativo de um agente de mudanças externo à empresa, o qual assume a responsabilidade de auxiliar os executivos e profissionais da referida empresa nas tomadas de decisões, não tendo, entretanto, o controle direto da situação.

A partir do momento em que se dá um conselho a uma pessoa que precisa fazer uma escolha, neste momento há prestação de uma consultoria.

"Consultor é a pessoa que tem certa influência sobre um indivíduo, um grupo ou uma organização, mas não tem poder direto para efetuar mudanças ou implementar programas." (BLOCK, 2013, p. 36). Quando se assume a responsabilidade direta da situação saímos do campo da consultoria e entramos no da gerência. O consultor precisa atuar de maneira diferente do gerente, pois o principal objetivo da consultoria é a aprendizagem do cliente.

O consultor deve se interar de todos os assuntos e acontecimentos que influenciarão na evolução do patrimônio da empresa, e segundo Sá (2008, p. 18) o "Papel, pois, do Consultor Contábil, do ponto de vista ético, é oferecer opiniões, orientações, no sentido de que os referidos propósitos sejam alcançados denunciando todos os desvios em relação a tal propósito". Se isso não ocorrer é porque o problema, pelo qual ela foi contratada, não foi solucionado de maneira correta.

Neste sentido, Block (2013, p. 39) trás uma completa definição:

Em seu uso mais geral, a consultoria descreve qualquer ação realizada em um sistema do qual não se faz parte. Uma conversa com alguém que está pedindo 
ajuda é um ato de consultoria. Um levantamento de problemas, um programa de treinamento, uma avaliação, um estudo - tudo isso são consultorias que visam à mudança. $O$ objetivo do consultor é se engajar em ações eficientes que levem pessoas ou organizações a se conduzirem de um modo diferente.

Ao pensar em utilizar-se dos serviços de consultoria é muito importante que a empresacliente avalie qual tipo é viável para melhor atender seus objetivos. Segundo Oliveira (2003, p. 51):

Consultor externo, representado por um consultor autônomo ou por um profissional de uma empresa de consultoria. [...] Consultor interno, representado por um funcionário da empresa-cliente, o qual presta serviços para serviços para áreas diversas da referida empresa.

Desta forma, a empresa pode escolher entre consultoria interna, realizada por funcionário da própria empresa, que conhece o seu funcionamento, tem acesso aos demais funcionários, porém tem menos experiência e menor aceitação dos superiores, ou consultoria externa, que é realizada por agente externo ao seu quadro de funcionários, possui maior experiência, imparcialidade e maior aceitação pelos altos escalões da empresa, porém possui menor conhecimento informal dos aspectos da empresa, menor acesso aos funcionários e é contratado para fins específicos e por período determinado.

“Eles acreditam ser necessário, para tal, apenas contratar o homem certo, mas não sabem onde encontrá-lo, como julgá-lo, como usá-lo e quais os parâmetros de avaliação de sua performance." (BERTI, 2009, p. 17).

O profissional que deseja seguir na área de consultor empresarial precisa delimitar qual será o produto ofertado ao mercado, uma vez que, a área de atuação é muito extensa e o conhecimento é limitando, não sendo possível saber tudo, sobre todos os assuntos.

“Para que o consultor possa desenvolver um bom trabalho de consultoria é necessário que haja um grau de confiança muito grande entre o consultor e os diretores da empresa, para evitar o truncamento de informações." (BERTI, 2009, p. 16).

Quando se trabalha com consultoria empresarial, se opera em dois níveis. O primeiro deles é o conteúdo, a parte explicita do trabalho, onde o cliente apresenta o problema da organização, e este pode ser a necessidade de um treinamento para melhorar o rendimento dos funcionários, ou a forma de tomar decisões que a organização usa, entre outros. É chamada explicita, pois diz respeito à parte técnica, racional e a coleta de dados feita a partir das discussões com o cliente. 0 segundo é o relacionamento com o cliente, ou seja, a parte implícita, pois os sentimentos serão sempre percebidos e nunca falados. Neste momento o consultor se depara com um de seus 
maiores dilemas: aceitação ou resistência. Logo, esta segunda fase acaba se tornando uma coleta de dados tão importante quanto à primeira.

E Block (2013, p. 48) enfatiza:

Uma vez que valoriza o lado afetivo do relacionamento como uma área que merece atenção, o segundo passo é aumentar seu nível de conforto ao expressar o que você esta sentindo no relacionamento. O terceiro passo é melhorar sua habilidade de expressar em palavras como percebe o relacionamento para que o cliente não aumente sua defensiva.

O relacionamento com o cliente vai muito além do conteúdo. É preciso que o contador perceba suas reais preocupações e pretensões, para então perceber as possibilidades e estabelecer um bom relacionamento com o cliente. Toda a experiência e conhecimento do assunto devem estar em equilíbrio com a interação estabelecida com o consultor. Desse modo, é o comportamento do consultor é outro fator preponderante. Uma organização passando por problemas com certeza esta insegura em relação ao que pode acontecer, e a ultima coisa de que ela precisa é de um consultor inseguro.

A atitude ideal para o consultor é a interativa, em que ele prepara o futuro e acredita que pode concretizar essa situação. Para ele, o futuro só depende do que faz agora e depois. Esta atitude consolida o pensamento estratégico do consultor empresarial. (OLIVEIRA, 2003, p. 147).

O comportamento deve ser consistente, controlado e decidido de maneira a passar credibilidade para que haja confiança por parte da organização. Caso isso não ocorra, as pessoas deixaram de acreditar na capacidade do contador, terão uma visão distorcida e passarão a não colaborar.

Aos gerentes, cabe a decisão de usar ou não as ações propostas, pois não faltam casos em que o relatório foi parar na prateleira, mesmo tendo levado tempo e dinheiro para ser elaborado. Block (2013, p. 84) demonstra que:

Esta é a mais profunda frustração da consultoria. Você sabe que suas recomendações são seguras e devem ser seguidas, mas não é responsável pela forma como a fornalha é operada e precisa aceitar esse fato. Você não é responsável se os clientes que receberam seu treinamento continuarem a agir como querem. Tudo o que se pode fazer é trabalhar com os clientes de modo a aumentar as probabilidades de eles seguirem suas orientações e se esforçarem para aprender a operar a fornalha ou se esforçar para lidar com os outros de uma forma diferente.

Para isso, o gerente deve ser bem treinado, garantindo que saberá usar as ações propostas com eficiência. A confiança e o compromisso devem ser conquistados e consolidados. Este 
processo faz parte de uma das etapas necessárias para a realização de uma boa consultoria que visa construir não só o compromisso, mas principalmente, reduzir a chance de perder o cliente.

Oliveira (2003, p. 24) faz uma orientação aos consultores:

Essa posição de alguns consultores que afirmam que não tem responsabilidade pelos resultados de seus projetos, pelo simples fato de não os terem implementado, pode ser considerada como uma das principais razões do distanciamento de algumas empresas para com os serviços de consultoria.

O consultor não é responsável pelo o que o gerente faz o com o projeto, mas se preocupa com o produto final, deseja que o trabalho por ele elaborado seja usado, e mais do que isso, que funcione de maneira eficaz.

E segundo Block (2013, p. 84) "sentimos a necessidade de apresentar nossos resultados concretos a fim de afastar qualquer dúvida sobre nosso trabalho ou de oferecer nossos serviços". Quando é prestado um serviço, seja ele profissional ou solidário, há uma necessidade de ver que o trabalho gerou resultados positivos. Com o consultor não é diferente.

"A contratação dos serviços de consultoria representa o momento-chave da interação entre a empresa-cliente e a empresa de consultoria ou o consultor." (OLIVEIRA, 2003, p. 78).

Frequentemente subestimada, a fase contratual é de suma importância para dar inicio ao trabalho com a organização. Contrato, nada mais é do que um acordo em que as partes interessadas expõem o que esperam um do outro e como será a forma de trabalho. E mais do que isso, Block (2013, p. 90) completa dizendo que:

O momento de máximo proveito para os consultores provavelmente seja obtido na fase de contratação do projeto. Certas possibilidades de impacto no projeto poderão se perder permanentemente caso não sejam perseguidas na contratação. O contrato define o encaminhamento do projeto, e é muito mais fácil negociar um novo contrato do que renegociar um antigo.

Dentre os requisitos necessários para o estabelecimento do contrato, estão o consentimento mútuo, onde ambos expressam o acordo de livre e espontânea vontade e as considerações válidas, para que nenhuma das partes se prejudique.

"A fase de contratação envolve negociar desejos, lidar com diferentes motivações, expressar preocupações sobre a exposição e a perda de controle, esclarecer o contrato para todas as partes e deixar o cliente seguro." (BLOCK, 2013, p. 94). Em geral, na reunião de contratação é necessário esclarecer expectativas um do outro, rejeitar ou rever o projeto se ficar perceptível que há menos de $50 \%$ de probabilidade de dar certo, dividir igualmente a responsabilidade e, principalmente, não prometer o que não pode ser cumprido. 
“A contratação assemelha-se a uma 'associação' bem sucedida entre consultor e cliente que ocorre paulatinamente a partir de um campo comum construído, uma linguagem familiar que aproxima as partes." (FEITOSA, PEDERNEIRAS, 2010, p. 150).

Estes são alguns pontos dos quais os consultores sentem dificuldades, não de realizar a ação em si, mas de valorizar a importância deles durante a negociação. Portanto, ter um diálogo com o cliente para que estes pontos sejam amplamente discutidos faz toda diferença para obter sucesso na consultoria.

Outra, que é sem dúvida, uma das maiores dificuldades encontradas pelos consultores durante a realização do seu trabalho é a resistência, a qual, Block (2013, p. 167) faz sua contribuição a respeito:

A parte mais difícil da consultoria é saber lidar com a resistência do cliente. Quando fazemos consultoria, é natural sentir que se pudermos apresentar nossas ideias de modo claro e lógico, e se visarmos sinceramente a atender aos interesses do cliente, ele respeitará nossa experiência e seguirá nossas sugestões. Logo descobrimos que por mais que nossa apresentação dos dados e nossas recomendações sejam razoáveis, os clientes mostram resistência.

O que muitos consultores não sabem é que a resistência faz parte do processo de mudanças pelo qual o cliente esta passando, interferindo diretamente no emocional. De acordo com Block (2013, p. 168) "lidar com a resistência envolve habilidade para: [...] não encarar a manifestação da resistência como algo pessoal ou como um ataque a você ou à sua competência".

"Os clientes resistentes estão se defendendo do fato de que terão de fazer uma escolha difícil, adotar medidas duras, confrontar uma realidade que emocionalmente tentaram evitar." (BLOCK, 2013, p. 177).

Ou seja, não levar a resistência como algo pessoal é o primeiro passo para superar tal obstáculo. O segundo passo é ouvir com atenção os questionamentos e responder de modo a confortá-los. Da mesma forma que os consultores devem ser autênticos e sinceros, essa fórmula deve se aplicar também aos gerentes, assim, eles iriam expor suas preocupações para que o consultor tome providencias e ao mesmo tempo não se sinta atacado.

E Berti (2009, p. 16) esclarece que a resistência vai além do problema:

“[...] Para muitos executivos a ajuda por consultoria simboliza o reconhecimento de fracasso, incompetência de gerir seu próprio negócio, falta de conhecimento técnico e administrativo etc. dado o alto envolvimento emocional no negócio, os fracassos da firma são para eles, fracassos pessoais."

É natural que as organizações privadas sejam muito competitivas e ter que recorrer à ajuda de terceiros pode ser visto como um sinal de fraqueza, pois esta organização que oferece um bem 
ou serviço no mercado se coloca na posição de cliente para a resolução de um problema o qual ela não teve condições de solucionar. E Block (2013, p. 184) completa dizendo que "a resistência vem, em parte, do constrangimento de ser dependente e pedir ajuda".

Portanto a resistência é um processo emocional e o consultor, no exercício de suas funções, deve oferecer um procedimento a fim de proporcionar resultados satisfatórios que minimizem o sofrimento que este problema causou ao gerente e a sua organização.

\section{CONCLUSÃO}

O profissional que pretende se consolidar no mercado e obter êxito na área de consultoria empresarial precisa ter competência para superar vários desafios, dentre eles, a dificuldades de relacionamento com o cliente, o comportamento do consultor, saber lidar com o fato de não ter controle direto da situação, atenção durante a fase contratual e a resistência a mudanças.

Após o estudo detalhado podemos concluir que para superar o problema de relacionamento com a organização é necessário diálogo e melhor interação com as pessoas que estão envolvidas direta ou indiretamente na execução das ações propostas, estabelecendo um relacionamento sólido, pautado em confiança, respeito e conscientização da sua importância.

No que se refere ao comportamento do consultor, este deve ser consistente, controlado e decidido, de maneira a passar credibilidade para que haja confiança por parte da organização.

Outro grande dilema do consultor é não ter controle direto da situação, desta forma a implementação do projeto dependerá do bom treinamento e aprendizado aplicado ao gerente e aos demais colaboradores.

Cabe-nos ressaltar a fase contratual dos serviços de consultoria que muitas vezes é subestimada, mas que é de grande importância, pois é o momento de negociar expectativas, demonstrar os problemas e as preocupações, dividir as responsabilidades, rejeitar ou rever o projeto e principalmente não prometer o que não pode ser cumprido.

E para finalizar, um dos grandes obstáculos encontrados foi a resistência do cliente para lidar com mudanças e com a sensação de frustração do cliente por não ter sido capaz de solucionar o problema precisando então, recorrer a consultoria. Portanto o consultor precisa estar atento a estes fatores emocionais e não encarar a resistência como um ataque a sua competência. Para superar esta dificuldade o recurso a ser utilizado é a compreensão e o amplo diálogo.

Sendo assim, conclui-se que o consultor precisa estar técnica e intelectualmente munido de atributos que garantam a qualidade do seu trabalho e preparado para lidar com as dificuldades emocionais encontradas. Seguindo os passos abordados neste artigo, o consultor estará 
caminhando para uma prestação de serviços de qualidade que atenda as expectativas da empresa cliente e obtenha êxito profissional.

\section{REFERÊNCIAS}

BERTI, Anélio, Manual Prático de Consultoria: Diagnóstico e Análise Empresarial - 2009 - Curtiba Ed. Jurirã, Ed - 22.

BLOCK, Peter, Consultoria Infalível - Um Guia Prático, Inspirador e Estratégico, 2013 - São Paulo M.Books do Brasil Editora Ltda. - Ed. 03.

OLIVEIRA, Dijalma de Pinho Rebolsas de, Manual de Consultoria Empresarial: Conceitos, Metodologia, Práticas - $4^{\circ}$ Ed. - São Paulo: Atlas - 2003.

SÁ, Antônio Lopes de, Consultoria e Análise Contábil, 2008 - Curitiba - Ed. Jurirã - Ed. 22. 